\title{
Partial trisomy 9p22 to 9p24.2 in combination with partial monosomy 9pter in a Syrian girl
}

\author{
Walid Al Achkar ${ }^{1 *}$, Abdulsamad Wafa ${ }^{1}$, Faten Moassass ${ }^{1}$, Thomas Liehr ${ }^{2}$
}

\begin{abstract}
Background: Partial trisomy of the short arm of chromosome 9 is among the most common autosomal structural chromosomal anomalies leading to chromosomal imbalance in human. Clinical characteristics are craniofacial dysmorphism including hypertelorism, prominent nose, deep-set eyes, and down-slanting palpebral fissures. The degree of clinical severity in partial trisomy $9 p$ roughly correlates with the size of the chromosomal imbalance. Therefore, breakpoints as well as clinical findings need to be precisely defined for differential diagnosis.

Results: Chromosomes of a young female were analyzed due to primary amenorrhea, short stature, developmental delay and a characteristic facial appearance. Cytogenetic analysis using GTG banding identified a karyotype 46, XX, add(9pter). Surprisingly the application of high resolution molecular cytogenetic techniques characterized a partial trisomy 9p24.2-p22 and partial monosomy 9pter-p24.2. To the best of our knowledge only four similar case were reported by now.

Conclusion: Attempts for genotype-phenotype correlations for partial trisomy $9 p$ might have been hampered by the fact that more complex, cryptic aberrations were neither considered nor detected in comparable clinical cases.
\end{abstract}

\section{Background}

Trisomy $9 \mathrm{p}$ is the fourth most frequent chromosome anomaly in life-born after trisomy 21,18 and 13 . A possible explanation might be that these chromosomes as well as $9 p$ are relatively gene poor [1-3]. The first case of trisomy 9p was described in 1970 [1]. Since then, more than 150 patients with partial or complete trisomy $9 p$ have been reported and this kind of chromosomal imbalance was characterized as a clinically recognizable syndrome. In most patients, the trisomic segment was transmitted from a parent carrying a reciprocal balanced translocation and only a small number arose from de novo duplications [3]. Rearrangements involving the distal region of the short arm of chromosome $9(9 \mathrm{p} 22$ to 9p24) are well described and may involve deletions or duplications resulting in the partial monosomy [4] or the partial trisomy $9 \mathrm{p}$ syndrome [3]. Characteristic clinical features of partial trisomy $9 p$ are mental retardation of various degree, short stature, craniofacial abnormalities, short fingers, simian crease, and single crease of

\footnotetext{
* Correspondence: scientific@aec.org.sy

${ }^{1}$ Molecular Biology and Biotechnology Department, Human Genetics

Division, Atomic Energy Commission, Damascus, Syria

Full list of author information is available at the end of the article
}

the fifth finger. Additional symptoms like microcephaly, cleft lip and palate, malformed ears, and skeletal, nail, cardiac, and genital anomalies have also been observed [3]. Partial monosomy $9 p$ or deletion $9 p$ is also reported to be associated with a well defined phenotype characterized by mental retardation, flat occiput, trigonocephaly, inner epicanthal folds, mild hypertelorism, strabismus, flat nasal bridge, long philtrum, high arched palate, and flat feet [4].

In clinical cytogenetics, the precise identification of the chromosomal abnormality is a key factor when considering genotype-phenotype correlation. Advances in molecular cytogenetics have allowed more precise analysis of complex chromosomal rearrangements, especially with FISH techniques, spectral karyotyping, conventional comparative genomic hybridization (CGH) and FISHbanding [5]. The possibilities of array-CGH also refined the accuracy of characterization of complex chromosomal anomalies, such as unbalanced intrachromosomal rearrangements in general [3].

Here we report a new case of partial trisomy $9 p$ involving cryptic monosomy of 9pter and discuss the possible impact of the detection of this case on the genotypephenotype correlation in trisomy $9 \mathrm{p}$. 

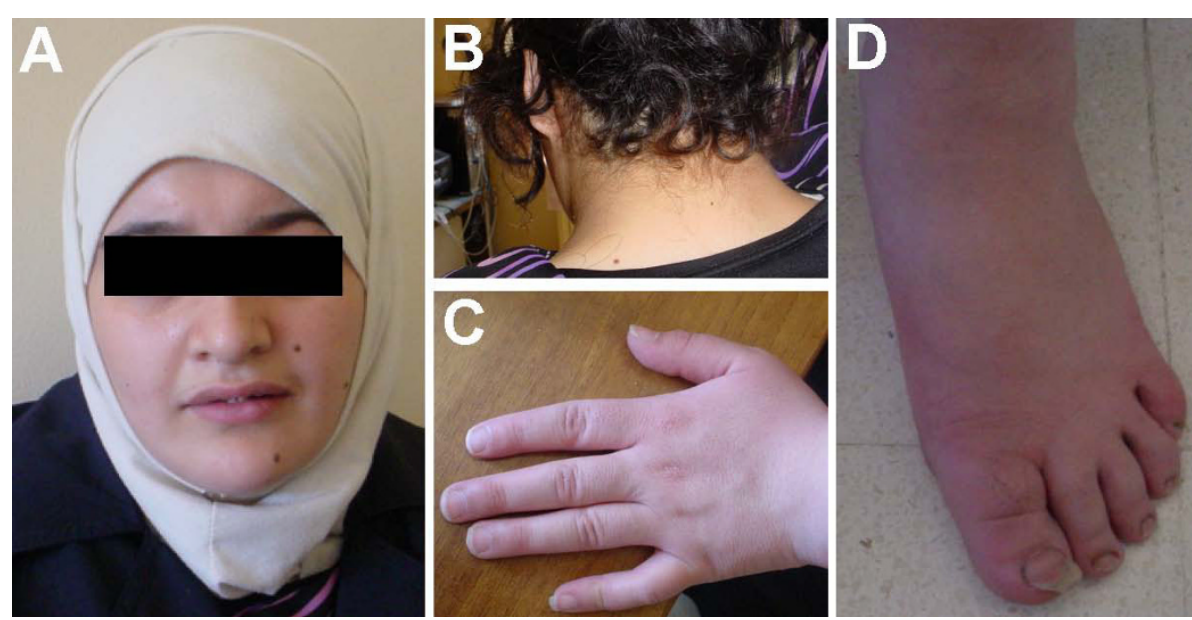

Figure 1 Typical phenotypical feature of the present patient: A) Facial appearance. B) Short neck and low set ears. C) Hand with short thumb and 5 th finger (present bilateral). D) Malformed nails on toes and flat feet (present bilateral)

\section{Case report}

The patient, a 20-year-old female, was the first child of healthy non-consanguineous 26-year old mother and 33-year-old father. The girl was born at 37th weeks of gestation with a birth weight of 3,500 g; birth length and head circumference were not recorded. She was referred to cytogenetic analysis at age of 20 years due to a primary amenorrhea. Clinical examination revealed short stature $(142 \mathrm{~cm})$, IQ at the lower limit of normal, growth and developmental delay, a characteristic facial appearance (downturned mouth, bulbous nose, short philtrum, wide neck, low set ears, deep set eyes, thick lips), single crease of the fifth finger, short thumb and fifth finger (bilateral), flat feet and malformed toe-nails (see Fig. 1). The bone age was 16 years and the external genitalia were normal.
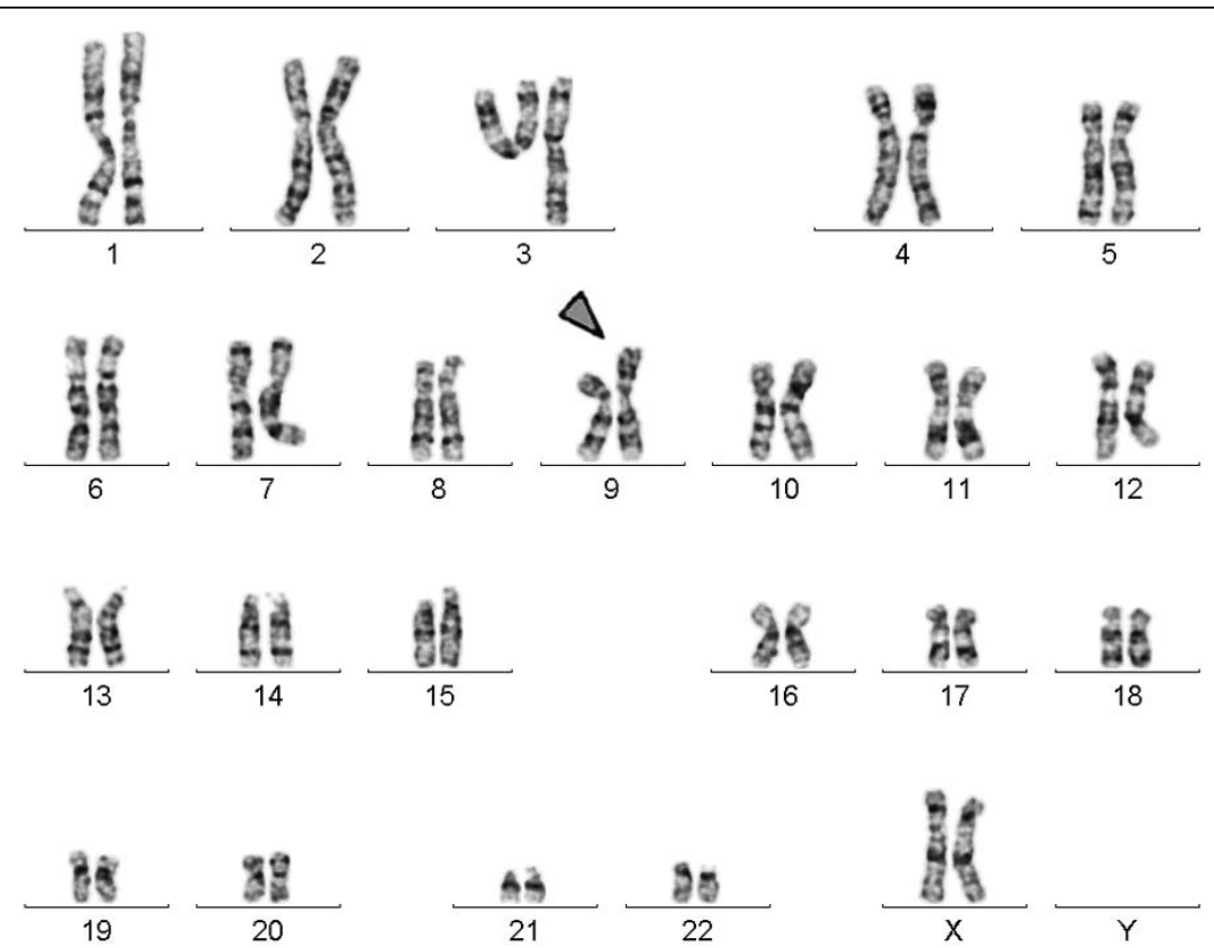

Figure 2 GTG-banding revealed a 46, XX, add(9pter); a duplication of $9 p$ material was suggested. The derivative chromosome is marked by an arrowhead. 
Ultrasound of pelvis revealed small uterus $(5 \times 2.5 \times 2$ $\mathrm{cm}$ ) with large ovaries (46 to $47 \mathrm{~mm}$ ) and polycystic ovaries. Hair distribution on the pubic is PHIII type, breast development is BIII type. Hormone levels: FSH 3.12 (normal up to 3.5-3.0 IU/l), LH 1.46 (normal up to $25 \mathrm{IU} / \mathrm{l}$ ) and prolactin 45.3 (normal up to $29 \mathrm{ng} / \mathrm{ml}$ ). The primary amenorrhea was treated by hormonal medication, leading to menstruation, which continued after drug was taken.

Banding in conventional cytogenetics detected a karyotype of 46, XX, add(9pter) in all cells (Fig. 2). This finding was further studied by molecular cytogenetics; applying aMCB [6] and the subtelomeric probe specific for $9 p$ (Fig. 3) the following result was obtained: 46, XX, $\operatorname{der}(9)(: p 22->$ p24.2::p24.2- > pter) (20). The karyotypes of the mother and the father were $46, \mathrm{XX}$ and $46, \mathrm{XY}$ respectively.

\section{Discussion}

Partial trisomy 9p was reported in numerous cases. It was seen as a result of different types of translocations, either de novo or inherited ones. The high frequency of the partial trisomy 9p may indicate a particular breakpoint sensitively of one or more regions of chromosome $9 p[1,3,7]$.

Here we present the first case having both: partial trisomy 9p24.2-p22 and partial monosomy 9pter-p24.2. Symptoms typical for partial trisomy $9 p$ were in the present patient short stature, short fingers and single crease of the fifth finger and nail anomalies. The finding of flat feet is more characteristic for partial monosomy of $9 p$. Typically observed in both conditions are mental retardation and craniofacial abnormalities. A similar case with partial trisomy 9p24.2-p21.3 and partial monosomy 9pter-p24.2 was recently reported [3]. There, as possibly specific features for this 'duplication/deletion 9p' condition, cleft palate and large eyes were discussed. However, both clinical features were absent in our patient. Besides, three other patients with partial trisomy 9p22.2p13.3/partial monosomy 9pter-p22.2 [8], partial trisomy 9p22.3-p12/partial monosomy 9pter-p22.3 [8], and partial trisomy 9p22-p13/partial monosomy 9pter-p22 [9] were published. For all these cases the derivative

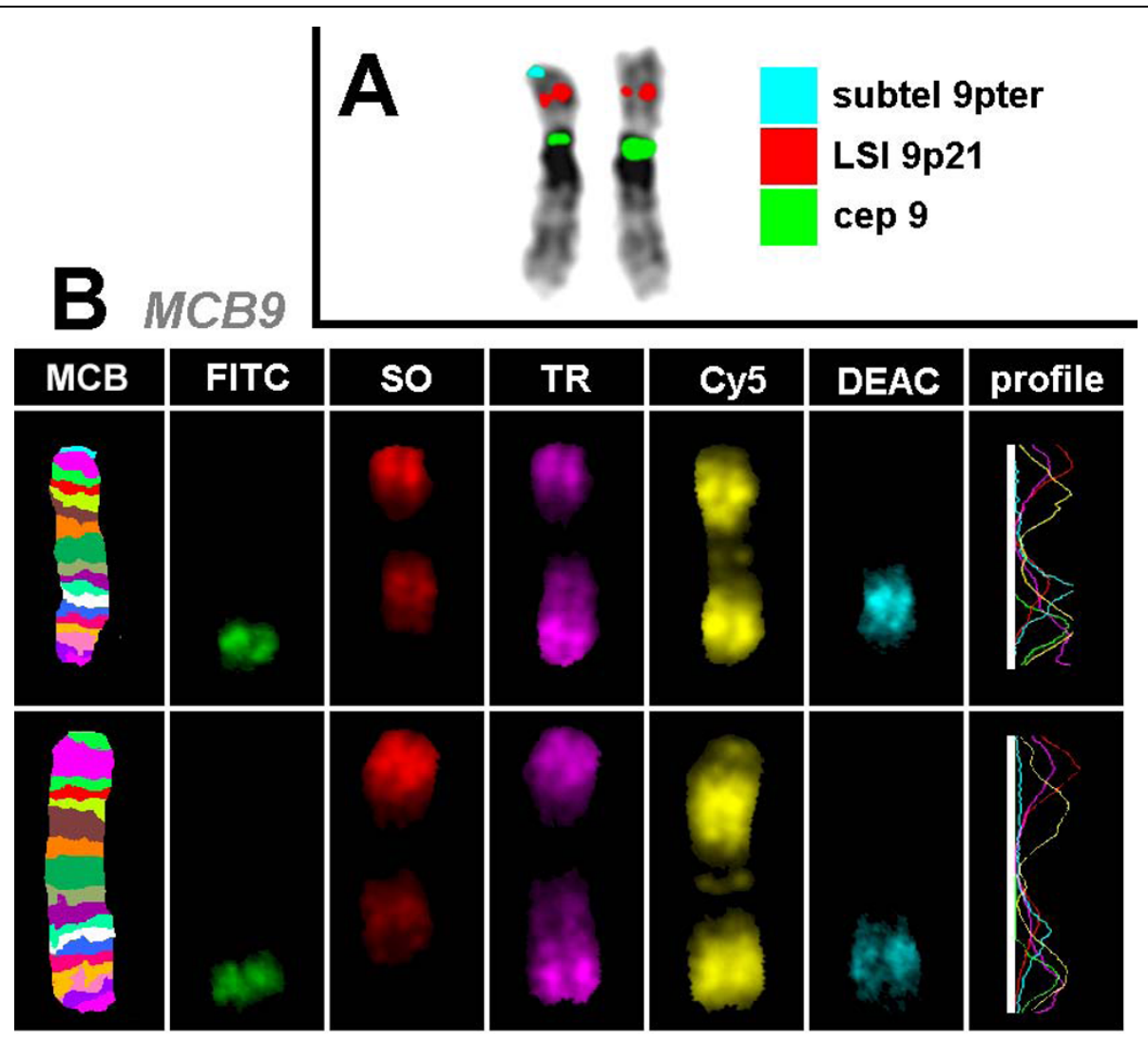

Figure 3 Karyotype and chromosomal aberrations were confirmed using molecular cytogenetic approaches. (A) A deletion on derivative chromosome 9pter was identified using the subtelomeric probe 9pter; application of the probe LSI 9p21 revealed that the breakpoint in the derivative chromosome 9 was distal from 9p21; the CEP 9 probe was used as a control. (B) The application of aMCB(9) characterized the additional material on derivative as chromosome 9 derived material and characterized the duplication of chromosome 9 in more detail. 
chromosome 9 finishes with apparently with an open break, similar as in comparable cases a neo-telomere formation might be considered here, as well [10].

The phenotypic effects of different trisomic regions of chromosome 9p were reviewed [3] comparing the cytogenetic and clinical findings of $\sim 150$ previously published cases with partial or complete trisomy 9p. The majority of these cases were caused by an unbalanced translocation involving other chromosomes, as well. The impact of these additional segments on the phenotype was hard to be determined. Furthermore, the so-called characteristic trisomy $9 p$ phenotype showed the best correlation with the 9p22 region [3]. Thus, the involvement of region $9 \mathrm{p} 22$ to9p24 in the present patient is in concordance with the general phenotype features of the partial trisomy $9 \mathrm{p}$ syndrome with mental retardation, developmental delay, short stature, characteristic facial appearance.

The critical region for viable partial deletions of the short arm of chromosome 9 seems to be relatively small. Up to present only comparatively minor terminal deletions of $9 p$, having relatively unspecific clinical signs, are reported $[4,11]$. Thus, overall, more cases characterized as having partial trisomy $9 \mathrm{p}$ syndrome might be found to be more complex than initially thought when analyzing them by FISH-banding or array-CGH approaches.

\section{Materials and methods}

\section{Chromosome analysis}

Chromosome analysis using GTG-banding was done according to standard procedures [12]. A total of 20 metaphases analyzed from stimulated peripheral blood culture were analyzed. Karyotypes were described according to the International System for Human Cytogenetic Nomenclature [13].

\section{Molecular cytogenetics}

Fluorescence in situ hybridization (FISH) was done according to manufacturer's instructions using a locus specific probe LSI 9p21, a subtelomeric (ST) probe for the short arm of chromosome 9 and a chromosome enumeration probe (CEP) 9 (Abbott Molecular/Vysis, USA). An array-proven multicolor banding probe (aMCB) set for chromosome 9 was applied as described [6,14]. A total of 20 metaphase spreads were analyzed, each using a fluorescence microscope (AxioImager.Z1 mot, Zeiss) equipped with appropriate filter sets to discriminate between a maximum of five fluorochromes and the counterstain DAPI (4,6- diamino-2phenylindole). Image capturing and processing were carried out using an ISIS imaging system (MetaSystems, Altlussheim, Germany) for the evaluation of aMCB.

\section{Consent}

Written informed consent was obtained from the patient for publication of this case report and accompanying images. A copy of the written consent is available for review by the Editor-in-Chief of this journal.

\section{Acknowledgements}

We thank Dr. I. Othman, the Director General of Atomic Energy Commission of SYRIA (AECS) and Dr. N. Mirali, Head of Molecular Biology and

Biotechnology Department for their support. This work was supported by the AECS and in parts by BMBF/DLR (BLR 08/004; ARM 08/001).

\section{Author details}

${ }^{1}$ Molecular Biology and Biotechnology Department, Human Genetics Division, Atomic Energy Commission, Damascus, Syria. ${ }^{2} J e n a$ University Hospital, Institute of Human Genetics, Jena, Germany.

\section{Authors' contributions}

AW and FM performed the cytogenetic studies in the present case and collected the data relative to this case report. WA supervised the cytogenetic analysis as Director of the HGD. AW, FM, TL did the molecular cytogenetic analysis and interpretation. TL drafted the paper, and all authors contributed to the finalizing of, and read and approved the final manuscript.

\section{Competing interests}

The authors declare that they have no competing interests.

Received: 11 August 2010 Accepted: 4 October 2010

Published: 4 October 2010

\section{References}

1. Rethoré MO, Larget-Piet L, Abonyi $\mathrm{D}$, Boeswillwald $\mathrm{M}$, Berger $\mathrm{R}$, Carpentier S, Cruveiller J, Dutrillau B, Lafourcade J, Penneau M, Lejeune J: [4 cases of trisomy for the short arm of chromosome 9. Individualization of a new morbid entity]. Ann Genet 1970, 13:217-232.

2. Krepischi-Santos AC, Vianna-Morgante AM: Disclosing the mechanisms of origin of de novo short-arm duplications of chromosome 9. Am J Med Genet 2003, 117A:41-46.

3. Hulick PJ, Noonan KM, Kulkarni S, Donovan DJ, Listewnik M, Ihm C, Stoler JM, Weremowicz S: Cytogenetic and array-CGH characterization of a complex de novo rearrangement involving duplication and deletion of $9 \mathrm{p}$ and clinical findings in a 4-month-old female. Cytogenet Genome Res 2009, 126:305-312.

4. Huret JL, Leonard C, Forestier B, Rethore MO, Lejeune J: Eleven new cases of del(9p) and features from 80 cases. J Med Genet 1988, 25:741-749.

5. Liehr T, Starke H, Weise A, Lehrer H, Claussen U: Multicolor FISH probe sets and their applications. Histol Histopathol 2004, 19:229-237.

6. Weise A, Mrasek K, Fickelscher I, Claussen U, Cheung SW, Cai WW, Liehr T, Kosyakova N: Molecular definition of high-resolution multicolor banding probes: first within the human DNA sequence anchored FISH banding probe set. J Histochem Cytochem 2008, 56:487-493.

7. Krepischi-Santos AC, Vianna-Morgante AM: Disclosing the mechanisms of origin of de novo short-arm duplications of chromosome 9. Am J Med Genet 2003, 117A:41-46.

8. Swinkels ME, Simons A, Smeets DF, Vissers LE, Veltman JA, Pfundt R, de Vries BB, Faas BH, Schrander-Stumpel CT, McCann E, Sweeney E, May P, Draaisma JM, Knoers NV, van Kessel AG, van Ravenswaaij-Arts CM: Clinical and cytogenetic characterization of 13 Dutch patients with deletion $9 p$ syndrome: delineation of the critical region for a consensus phenotype. Am J Med Genet A 2008, 146A:1430-1438.

9. Teebi AS, Gibson L, McGrath J, Meyn MS, Breg WR, Yang-Feng TL: Molecular and cytogenetic characterization of 9p-abnormalities. Am J Med Genet 1993, 46:288-292.

10. Kulikowski LD, Christ LA, Nogueira SI, Brunoni D, Schwartz S, Melaragno MI: Breakpoint mapping in a case of mosaicism with partial monosomy 9 p23 $\rightarrow$ pter and partial trisomy 1q41 -> qter suggests neo-telomere formation in stabilizing the deleted chromosome. Am J Med Genet $A$ 2006, 140:82-87. 
11. Techakittiroj C, Kim KC, Andersson H, Li MM: 9p subtelomere deletion: pathogenic mutation or normal variant? Beijing Da Xue Xue Bao 2006, 38:92-93.

12. Claussen U, Michel S, Mühlig P, Westermann M, Grummt UW, KromeyerHauschild K, Liehr T: Demystifying chromosome preparation and the implications for the concept of chromosome condensation during mitosis. Cytogenet Genome Res 2002, 98:136-146.

13. Shaffer L, Slovak M, Cambell L, (eds): ISCN (2009): An International System for Human Cytogenetic Nomenclature. Karger Basel 2009.

14. Liehr T, Heller A, Starke H, Rubtsov N, Trifonov V, Mrasek K, Weise A, Kuechler A, Claussen U: Microdissection based high resolution multicolor banding for all 24 human chromosomes. Int I Mol Med 2002, 9:335-339.

doi:10.1186/1755-8166-3-18

Cite this article as: Al Achkar et al:: Partial trisomy 9p22 to 9p24.2 in combination with partial monosomy 9pter in a Syrian girl. Molecular Cytogenetics 2010 3:18.

\section{Submit your next manuscript to BioMed Central} and take full advantage of:

- Convenient online submission

- Thorough peer review

- No space constraints or color figure charges

- Immediate publication on acceptance

- Inclusion in PubMed, CAS, Scopus and Google Scholar

- Research which is freely available for redistribution

Submit your manuscript at www.biomedcentral.com/submit 